\title{
Cytotoxicity Evaluation of Minimum Antibacterial Values of Different Medicaments Used in Endodontic Regenerative Procedures
}

\author{
Mehrfam Khoshkhounejad ${ }^{1,2}$ \\ Mohammadreza Sharifian ${ }^{1}$ \\ ${ }^{1}$ Department of Endodontics, School of Dentistry, Tehran University \\ of Medical Sciences, Tehran, Iran \\ 2Dental Research Center, Dentistry Research Institute, Tehran \\ University of Medical Sciences, Tehran, Iran \\ ${ }^{3}$ Department of Microbiology, School of Medicine, Tehran \\ University of Medical Sciences, Tehran, Iran
}

Fereshteh Jabalameli ${ }^{3} \quad$ Mohammad Emaneini ${ }^{3}$

Eur J Dent 2019;13:514-520

\begin{abstract}
Address for correspondence Mohammadreza Sharifian, DDs, DolBE, Department of Endodontics, School of Dentistry, Tehran University of Medical Sciences, North Karegar, Tehran, Iran. Postal code:1439955991 (e-mail: sharifian.mr.tums@gmail.com).
\end{abstract}

\begin{abstract}
Keywords

- antibiotics

- regenerative

endodontics

- stem cells

- toxicity

Objectives This study aimed to evaluate the cytotoxicity of minimum antibacterial values of medicaments used in endodontic regeneration on stem cells.

Materials and Methods "Minimum inhibitory concentration," "minimum bactericidal concentration," and "minimum biofilm inhibitory concentration" of triple and double antibiotic paste, a modified triple antibiotic paste (minocycline replaced by clindamycin), Augmentin, and calcium hydroxide were determined using Enterococcus faecalis (ATCC 29212) by microtiter plate method. Direct cytotoxic effects of drugs were evaluated by lactate dehydrogenase and water-soluble tetrazolium salt- 1 assays using stem cells of apical papilla obtained from immature third molars via enzymatic digestion.

Statistical Analysis Data were analyzed using IBM SPSS Statistics 24, one-way analysis of variance and post hoc comparisons. The statistical power was set at $p<0.05$.

Results All medicaments caused similar cytotoxicity and cell proliferation at "minimum inhibitory concentration" ( $p>0.05$ ) except Augmentin which was significantly more toxic than others $(p<0.05)$. At "minimum bactericidal concentration," calcium hydroxide was more toxic than other drugs $(p<0.001)$, but its adverse effect on cell proliferation was the same as Augmentin $(p>0.05)$. Triple and double antibiotic paste revealed similar favorable effects in terms of toxicity and proliferation rate at most of the tested concentrations $(p>0.05)$. At "minimum biofilm inhibitory concentration" both the modified paste and Augmentin caused less proliferation rate than triple and double antibiotic paste ( $p<0.001$ and $p<0.05$, respectively) and Augmentin induced more cytotoxicity $(p<0.05)$.

Conclusions Considering the antimicrobial potency, triple antibiotic paste seems to be the safest drug for the stem cells of apical papilla, while Augmentin may have some adverse effects.
\end{abstract}

\section{Introduction}

Endodontic treatment of traumatized immature permanent necrotic teeth is a clinical challenge. Among different treatment protocols, regenerative endodontic procedures (REPs) that are defined as "biologically based" treatments seem to offer a better outcome in terms of tooth development and survival. ${ }^{1,2}$ Induced bleeding in REPs provides 
a source of stem cells that may originate from the apical papilla and play an important role in forming the desired tissues. ${ }^{3}$ Given that in these procedures root canal debridement is mainly provided by chemical disinfection rather than mechanical instrumentation, it is important to maintain a balance between antibacterial effectiveness of the chemicals and their innocuousness for stem cells. ${ }^{4,5}$

Calcium hydroxide $\left[\mathrm{Ca}(\mathrm{OH})_{2}\right]$ has been used as an antibacterial agent in regenerative endodontics. ${ }^{6,7}$ Due to certain disadvantages, antibiotics seemed to be an appropriate alternative. ${ }^{8}$ Different antibiotic mixtures such as triple antibiotic paste (TAP: Metronidazole, Minocycline and ciprofloxacin), double antibiotic paste (DAP: metronidazole and ciprofloxacin), and modified triple antibiotic paste (MTAP: minocycline component replaced) have been used..$^{9,10}$ In a few studies, Augmentin has also been reported as an effective antibacterial agent in regenerative endodontics ${ }^{11,12}$ and maybe useful in case of no allergy to penicillin. Concerns still remain in terms of tooth discoloration ${ }^{13}$ and adverse effect of high concentrations of antibiotics on stem cell integrity. ${ }^{12,14,15}$

Still, there is little reliable information about the most effective intracanal disinfecting agent or the best concentration of available drugs that could provide maximum antimicrobial efficacy along with minimal damage to the viability and function of stem cells. ${ }^{16}$

Two aims were pursued in this in vitro study: first, to determine the minimum inhibitory concentration (MIC), minimum bactericidal concentration (MBC), and minimum biofilm inhibitory concentration (MBIC) of $\mathrm{Ca}(\mathrm{OH})_{2}, \mathrm{TAP}, \mathrm{DAP}$, MTAP (minocycline replaced by clindamycin) and Augmentin against Enterococcus faecalis (ATCC 29212) using microtiter plate method and second, to evaluate the cytotoxic effect of mentioned concentrations of intracanal medicaments on stem cells of apical papilla (SCAP) using lactate dehydrogenase (LDH) and water-soluble tetrazolium salt (WST-1) assays. As we know, this is the first study that investigates the cytotoxicity of minimum inhibitory values of drugs using Enterococcus faecalis (ATCC 29212) on the SCAP. ${ }^{17,18}$

Reports are also available about antibacterial effectiveness of TAP, DAP, and $\mathrm{Ca}(\mathrm{OH})_{2}{ }^{18}$ To the best of our knowledge, there is no report about MIC, MBC, and MBIC measurement of the modified triple antibiotic mixtures that have incorporated clindamycin instead of minocycline.

\section{Materials and Methods}

\section{Primary Cell Culture}

SCAP were obtained from intact immature mandibular third molars of a patient by enzymatic digestion method. ${ }^{19}$ Informed consent was obtained and all procedures were approved by the human experimental committee of dental school of Tehran University of medical sciences, Tehran, Iran (IR.TUMS.DENTISTRY.REC.1396.2813).

The cells were cultured in Dulbecco's modified eagle's medium (DMEM) (Gibco; Carlsbad, California, United States) supplemented with $10 \%$ fetal bovine serum, $1 \times$ L-glutamine, penicillin $(100 \mathrm{U} / \mathrm{mL})$, and streptomycin $(100 \mathrm{U} / \mathrm{mL})$ and then grown to 70 to $80 \%$ confluency. SCAP after third and fourth passages, were harvested and used in this study.

\section{Medicament Preparation}

A $10 \mathrm{mg} / \mathrm{mL}$ dilution of TAP (metronidazole, ciprofloxacin, and minocycline), MTAP (metronidazole, ciprofloxacin, and clindamycin) and DAP (metronidazole, ciprofloxacin) were prepared by dissolving equal portions of USP (United States Pharmacopeia)-grade antibiotic powders (Sigma-Aldrich Chemie $\mathrm{GmbH}$, Germany) in distilled water to prepare stock solutions. The dilution of stock solution was defined based on previous studies and a pilot study that determined MBIC measurements.

For preparing TAP and MTAP, $16.5 \mathrm{mg}$ and for DAP, $25 \mathrm{mg}$ of each antibiotic was used and the powder mixture was dissolved in $5 \mathrm{~mL}$ distilled water.

For Augmentin a $10 \mathrm{mg} / \mathrm{mL}$ stock solution was prepared by dissolving $10 \mathrm{mg}$ of drug in $1 \mathrm{~mL}$ distilled water. $\mathrm{Ca}(\mathrm{OH})_{2}$ solution was prepared by stirring $16 \mathrm{mg}$ of $\mathrm{Ca}(\mathrm{OH})_{2}$ powder (Golchaico, Ir) in $1 \mathrm{~mL}$ of distilled water, according to Sabrah et al. ${ }^{18}$

\section{MIC, MBC, and MBIC Determination}

Enterococcus faecalis (ATCC 29212) was used as the standard bacterial strain to define antimicrobial efficacy of drugs. It is the most suitable strain for determining MIC of medicaments using dilution methods, according to CLSI guideline. ${ }^{20}$

Minimum inhibitory concentration, which is the lowest concentration of a chemical which prevents visible growth of a bacterium, ${ }^{21}$ was determined by a two-fold dilution method. ${ }^{18}$

Minimum bactericidal concentration is the lowest concentration of an antibacterial agent required to kill a particular bacterium. ${ }^{18,21}$ To determine MBC, samples were taken from the wells of test drugs, at concentrations equal to and higher than MIC, and subcultured on brain heart agar plates and incubated for 24 hours. MBC was represented as no bacterial growth on agar plates during the aforementioned time. ${ }^{18}$

Minimum biofilm inhibitory concentration, which is the lowest concentration of an agent that inhibits the visible biofilm formation of a microorganism, ${ }^{22}$ was determined by microtiter plate method. ${ }^{18}$

\section{LDH Assays}

Subconfluent SCAP were seeded into a 96-well plate $(10,000$ cells/well) and incubated for 24 hours in DMEM supplemented with $10 \%$ fetal bovine serum, to allow the cells to attach. After 24 hours, the old medium was removed, and the cells were incubated with serum-free DMEM in the presence of MIC, MBC, and MBIC of test drugs for 3 days. SCAP incubated without any medicament in serum-free DMEM were used as negative control (low control), and SCAP incubated with lysis solution were used as positive control (high control). After the mentioned time, supernatants were collected and utilized for LDH assay. The levels of LDH, released by the cells into the medium due to membrane damage, were determined by Takara LDH Cytotoxicity Detection Kit (MK401; Takara, Japan). Briefly, $100 \mu \mathrm{L}$ of SCAP culture media were transferred into another 96-well plate. Then $100 \mu \mathrm{L}$ of reaction mixture, prepared according to manufacturer 
protocol, was added and mixed in each well and the plate was incubated for 30 minutes at room temperature. BioTek microplate reader (BioTek Instruments, Inc. Winooski, VT, United States) was used to quantitatively measure the calorimetric change at a wavelength of $490 \mathrm{~nm}$. The following equation was used to calculate the percentage of cytotoxicity:

Cytotoxicity $(\%)=($ experimental value-low control $) /$ (high control-low control) $\times 100$

The high control cytotoxicity percentage was considered to be $100 \%$; while the low control was $0 \%$ (-Supplementary Table 1, available in online version only).

\section{WST-1 Assays}

WST-1 assay (PreMix WST-1 Cell Proliferation Assay system; MK400, Takara, Japan) was used to measure mitochondrial dehydrogenase activity of treated and nontreated SCAP. Treated SCAP were exposed to certain defined concentrations of different test drugs and fulfilled 3 days of incubation; while untreated SCAP, which were considered as control group, had no drug exposure. After collecting the medium for the LDH assay and washing the cells with phosphate buffer solution, $20 \mu \mathrm{L}$ of PreMix WST-1 solution and serum-free DMEM was added to SCAP to maintain a final dilution of $1: 10$. Then, cells were incubated at $37^{\circ} \mathrm{C}$ in a humidified atmosphere containing $5 \% \mathrm{CO}_{2}$ for 4 hours. Ultimately, BioTek microplate reader (BioTek, United States) was used to measure the optical absorbance of each well at $420 \mathrm{~nm}$. The following equation was used to calculate the percentage of cell viability.

Cell viability $(\%)=$ (absorbance value of the treated cells $/$ absorbance value of untreated cells) $\times 100$

The viability percentage of the untreated cells was considered $100 \%$ (-Supplementary Table 1, available in online version only).

Comparisons were made using one-way analysis of variance (ANOVA) and post hoc tests (Tukey and Games-Howell). The statistical power was set at $p<0.05$.

\section{Results}

MIC, MBC, and MBIC of tested medicaments are shown in - Table 1.

Based on the results of LDH assay, all the tested concentrations of medicaments were significantly less toxic than the high control sample $(p<0.001)$, with the exception of MBC of $\mathrm{Ca}(\mathrm{OH})_{2}(p>0.05)$ (-Fig. 1) (-Supplementary Table 2, available in online version only).

Table 1 MIC, MBC, and MBIC of tested drugs in $\mathrm{mg} / \mathrm{mL}$

\begin{tabular}{|l|l|l|l|}
\hline Test drugs & \multicolumn{3}{|c|}{ Concentrations $(\mathrm{mg} / \mathrm{mL})$} \\
\hline & MIC & MBC & MBIC \\
\hline TAP & 0.00006 & 0.00195 & 0.00195 \\
\hline DAP & 0.007 & 0.031 & 0.156 \\
\hline MTAP & 0.000976 & 0.00781 & 0.25 \\
\hline Augmentin & 0.000976 & 0.00195 & 0.00195 \\
\hline $\mathrm{Ca}(\mathrm{OH})_{2}$ & 0.2 & 16 & Not defined $^{\text {a }}$ \\
\hline
\end{tabular}

Abbreviations: DAP, double antibiotic paste; MBC, minimum bactericidal concentration; MBIC, minimum biofilm inhibitory concentration; MIC, minimum inhibitory concentration; MTAP, modified triple antibiotic paste; TAP, triple antibiotic paste.

aBacterial growth observed at all concentrations in microtiter plate method, which made it impossible to determine MBIC value for calcium hydroxide.

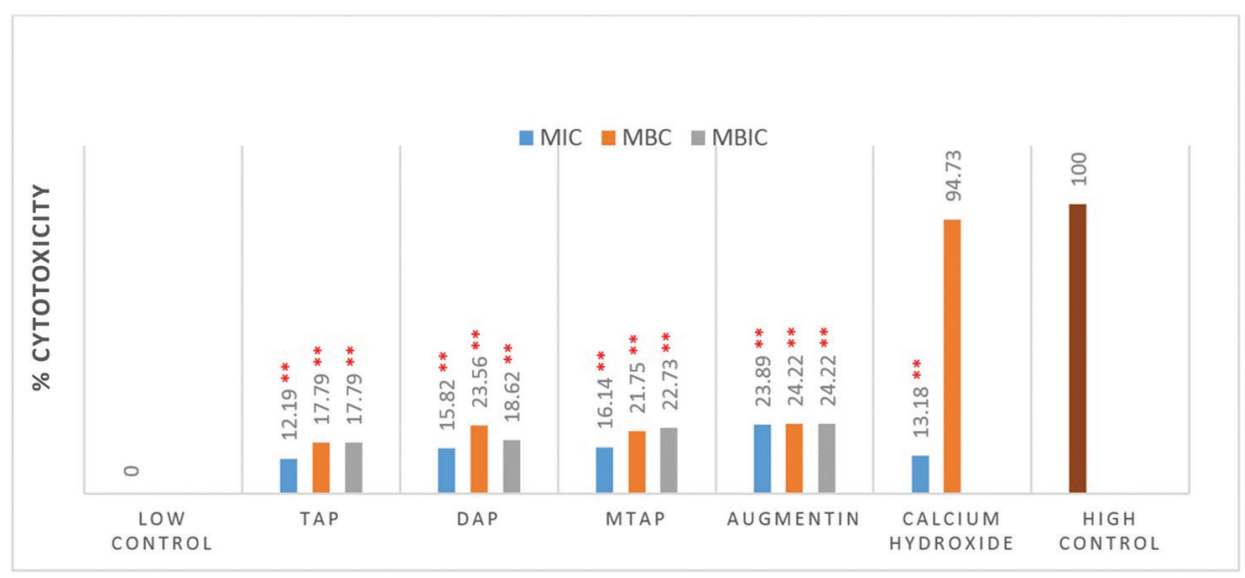

Fig. 1 Cytotoxicity (\%) of the tested medicaments at MIC, MBC, and MBIC. ${ }^{* *}$ denotes a significant difference relative to the high control $(p<0.001)$. DAP, double antibiotic paste; MBC, minimum bactericidal concentration; MBIC, minimum biofilm inhibitory concentration; MIC, minimum inhibitory concentration; TAP, triple antibiotic paste. 
According to WST-1 assay, with increasing drug concentration cell viability showed a decreasing trend, except for TAP and DAP. Reduced cell viability was statistically significant at MBC and MBIC of Augmentin compared with TAP and DAP $(p<0.05)$ and also at $\mathrm{MBC}$ of $\mathrm{Ca}(\mathrm{OH})_{2}$ compared with TAP, DAP, and MTAP $(p<0.001)$. Increased concentration of TAP and DAP could not adversely affect cell viability $(p>0.05)$ ( - Fig. 2) ( - Supplementary Table 2; available in online version only).

LDH assay evaluation of the tested drugs presented higher cytotoxicity of Augmentin at its MIC in comparison with other medicaments $(p<0.05)$ ( - Fig. 3). Cytotoxic effect of TAP, DAP, MTAP, and $\mathrm{Ca}(\mathrm{OH})_{2}$ was similar at MIC $(p>0.05)$. Comparing the toxicity of drugs at $\mathrm{MBC}$ revealed a significantly higher cytotoxicity of $\mathrm{Ca}(\mathrm{OH})_{2}$ than the other medicaments $(p<0.001)$, while others caused similar results $(p>0.05)$. At MBIC, Augmentin was significantly more cytotoxic than TAP and DAP $(p<0.05)$. TAP and DAP had similar cytotoxic effects at this concentration $(p>0.05)(-$ Fig. 3) (-Supplementary Table 2; available in online version only).

According to WST-1, the lowest proliferation rate at MIC value was also attributed to Augmentin that was significantly lower than most of the other drugs $(p<0.05)(-$ Fig. 4$)$. At this concentration, TAP could cause a notable proliferation rate that was significantly higher than DAP $(p<0.05)$. Checking $\mathrm{MBC}$ value indicated that the least proliferation rate was related to $\mathrm{Ca}(\mathrm{OH})_{2}(p<0.001)$ followed by Augmentin $(p<0.05)$. TAP caused a superior cell proliferation in comparison with other medicaments at MBC $(p \leq 0.001)$, but there was no significant difference between TAP and DAP in this regard $(p>0.05)$ (-Supplementary Table 2 ; available in online version only).

At MBIC, again TAP caused a significantly superior proliferation rate in comparison with other drugs $(p<0.001)$

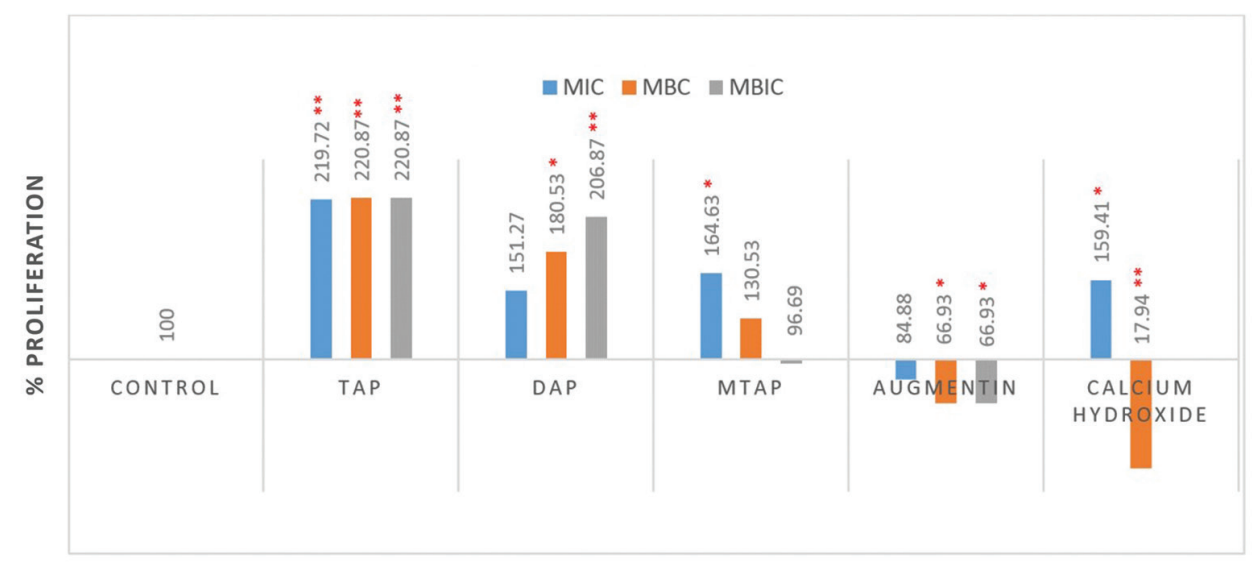

Fig. 2 Cell viability (\%) related to MIC, MBC, and MBIC of the tested medicaments. ${ }^{* *}$ denotes a significant difference relative to control $(p<0.001) .{ }^{*}$ denotes a significant difference relative to control $(p<0.05)$. DAP, double antibiotic paste; MBC, minimum bactericidal concentration; MBIC, minimum biofilm inhibitory concentration; MIC, minimum inhibitory concentration; DAP, double antibiotic paste; TAP, triple antibiotic paste.

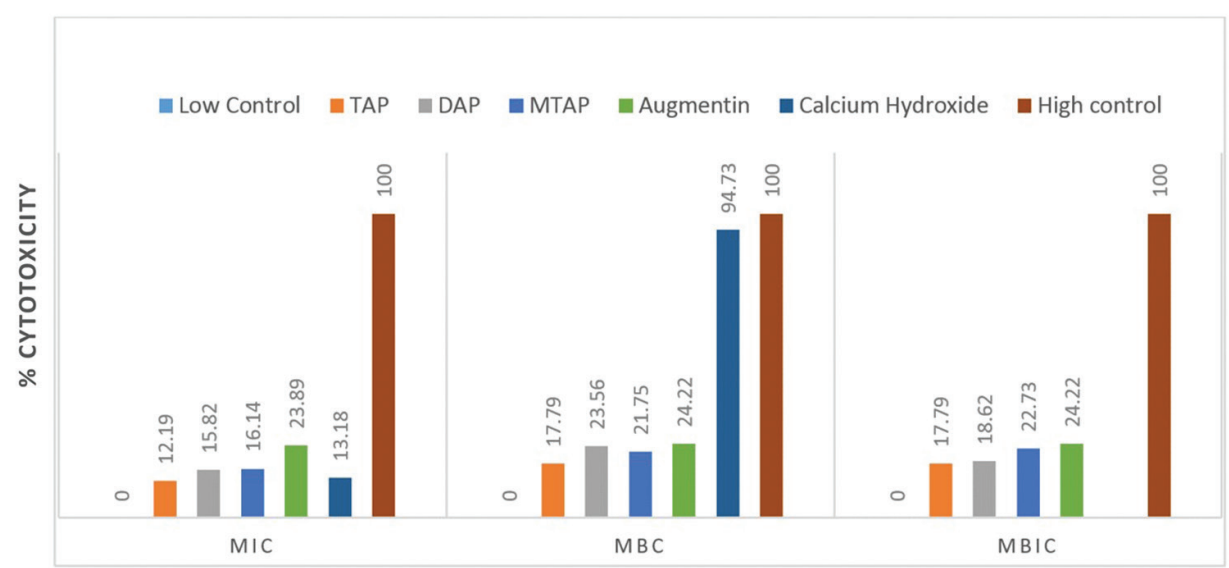

Fig. 3 Comparison of cytotoxicity (\%) induced by MIC, MBC, and MBIC of the tested medicaments. DAP, double antibiotic paste; MBC, minimum bactericidal concentration; MBIC, minimum biofilm inhibitory concentration; MIC, minimum inhibitory concentration; DAP, double antibiotic paste; TAP, triple antibiotic paste. 


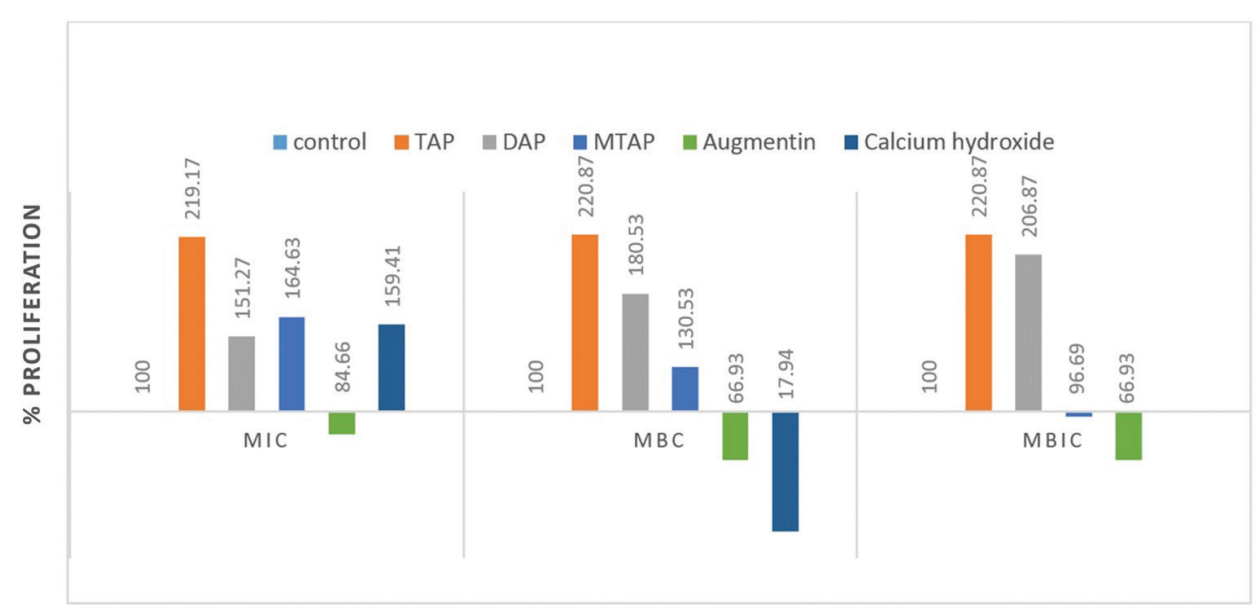

Fig. 4 Comparison of cell viability (\%) related to MIC, MBC, and MBIC of the tested medicaments. MBC, minimum bactericidal concentration; MBIC, minimum biofilm inhibitory concentration; MIC, minimum inhibitory concentration; DAP, double antibiotic paste; TAP, triple antibiotic paste.

except DAP $(p>0.05)$. DAP could also cause significantly higher proliferation rate than other drugs $(p<0.05)$. Both Augmentin and MTAP represented the same adverse effect on cell proliferation $(p>0.05)$ ( - Fig. 4) ( - Supplementary Table 2; available in online version only).

\section{Discussion}

Providing a microbe free environment by means of medicaments that would cause the least toxic effect on stem cells is mandatory for the regeneration of dentin-pulp complex. ${ }^{23}$ Attempts to select a suitable medicament are still ongoing and different dilutions have been studied for cytotoxicity and antibacterial effect. ${ }^{12,14,15,24,25}$ Unlike previous studies, this study aimed to consider the cytotoxic effect of "minimum antimicrobial inhibitory dilutions" of different medicaments on the stem cells.

Concerns about the safety of stem cells have led to the tendency of using lesser concentrations of intracanal medicaments. ${ }^{12,25}$ Since low doses of antibiotics have been utilized in manufacturing some antibiotic releasing scaffolds, ${ }^{26-28}$ and because of the desirability of slow release of low doses of medicaments from these scaffolds, it is important to investigate toxicity of the low concentrations of antibiotics on different kinds of stem cells as well as their antibacterial effectiveness against different bacterial species and biofilms that may help in the technology of manufacturing scaffolds.

For toxicity evaluation, different methods have been used so far. ${ }^{12,14,15,24}$ In the category of spectrophotometry, both LDH and WST- 1 assays are widely used for cell death studies. ${ }^{29} \mathrm{LDH}$ assay is related to the cell death, while WST- 1 assay reflects the mitochondrial metabolism and rather demonstrates the viability of cells. To overcome the shortcomings of these tests, it is recommended to incorporate their results to derive more reliable knowledge of cell cytotoxicity and proliferation. . $5,29,30^{2}$

In the current study, the tested concentrations of intracanal medicaments were very low and according to the LDH assay, minimally toxic and nonlethal ( $\mathbf{- F i g}$. 1). However, it is possible to detect changes in mitochondrial activity level before cell membrane degradation and LDH release using WST-1 assay. Considering the findings of WST- 1 assay, it seems that even low concentrations of chemicals might have caused some cellular damage not necessarily leading to death but affecting cells function and behavior ( - Fig. 2). Thus, WST-1 assay may be more illustrative when the effects of low concentrations of medicaments on the function of stem cells are to be investigated. Similar observations have been reported by other researchers, such as Labban et $\mathrm{al}^{15}$ and Sabrah et al. ${ }^{24}$.

In accordance with current findings, many studies have confirmed reduced cytotoxicity of medicaments in lower concentrations. $12,14,15,24,25,31$ Although the results may not be completely comparable to the current study because of differences in methods and materials.

One of the noticeable findings of the current study is the promotive effect of TAP on SCAP proliferation at all the tested concentrations. This may suggest a positive effect of some medicaments while diluted by body fluids which is in accordance with the findings of Labban et al. ${ }^{15}$ DAP behaved similarly in terms of cell toxicity in range of tested concentrations. This finding may suggest similar behavior of diluted antibiotics, while they may have different effects at higher concentrations.

In this study, the amount of $\mathrm{Ca}(\mathrm{OH})_{2}$ for preparing stock solution was selected due to Sabrah's study. ${ }^{18}$

In contrast to Sabrah et $\mathrm{al}^{18}$ in this study only MIC and MBC values could be measured for $\mathrm{Ca}(\mathrm{OH})_{2}$. However, to achieve $\mathrm{MBC}$, a prominent increase in the drug concentration was necessary. This difference might be related to the different commercial compositions used. It was not possible to measure MBIC of $\mathrm{Ca}(\mathrm{OH})_{2}$, because it was incapable of preventing biofilm formation even at the highest concentration that could be practically drawn up into the pipette. It is noteworthy that the MIC of $\mathrm{Ca}(\mathrm{OH})_{2}$ caused a significant increase in cell proliferation in comparison to the control group. This favorable effect was not achieved by higher concentrations of this medicament. This finding was in accordance with 
Labban et al, who reported that $2.5 \mathrm{mg} / \mathrm{mL}$ of $\mathrm{Ca}(\mathrm{OH})_{2}$ was the highest nontoxic concentration..$^{15}$ They had discussed that some drugs may have a positive effect on cell growth and proliferation at low-concentration while exhibiting toxic effect at higher concentrations. ${ }^{15}$

This finding is also reported by Alghilan et $\mathrm{al}^{31}$ and Hosseini Matin et a ${ }^{132}$ who did not support using the higher concentrations of $\mathrm{Ca}(\mathrm{OH})_{2}$, while others like Ruparel et $\mathrm{a}^{12}$ and Althumairy et $\mathrm{al}^{14}$ found $\mathrm{Ca}(\mathrm{OH})_{2}$ to be safe enough even in high concentrations.

Based on the current study, using $\mathrm{Ca}(\mathrm{OH})_{2}$ in dilutions less than pasty consistency may provide better results in term of cell viability.

On the other hand, current study supports the idea that some antibacterial medicaments may represent their acceptable antibacterial efficacy at higher concentrations that maybe harmful for the viability and function of stem cells. If proved in further studies, the use of some medications may be revised in future endodontic regenerative protocols.

Although the amount of antibacterial inhibitory concentrations of Augmentin was much lower than some other medicaments such as $\mathrm{Ca}(\mathrm{OH})_{2}$ and MTAP, these values imposed a considerable adverse effect on SCAP. This finding may suggest that the cytotoxicity of certain chemicals depends on their inherent properties, rather than due to the increase in their concentration.

In this study, the unfavorable effect of low concentrations of Augmentin on SCAP suggests the need for further studies before recommending this drug as an antibacterial medicament in REPs.

This study suggests that effective antibacterial concentrations of intracanal medicaments used in REPs may have different effects on the integrity of stem cells. TAP was well tolerated by SCAP; Augmentin and high concentrations of $\mathrm{Ca}(\mathrm{OH})_{2}$ revealed some adverse effects at their effective antimicrobial values. This idea has to be further tested in other preclinical studies using a range of bacterial species. In addition, proper antimicrobial effectiveness of the mentioned concentrations must be confirmed on polymicrobial flora of irregular root canal space of infected immature permanent teeth in clinical studies with higher level of evidence.

\section{Note}

The manuscript has been read and approved by all the authors prior to its submission and they have agreed to submit the manuscript to the Journal of European Journal of Dentistry.

Authors confirm that the article is original, has not been previously published, is not under consideration elsewhere, and will not be submitted to other publications as long as it is being processed by this journal.

The article does not contain any items subjected to copyright regulations.

\section{Funding}

This study was supported by Tehran University of Medical Sciences (grant no: 35692).

\section{Conflict of Interest}

None declared.

\section{Acknowledgments}

Our grateful thanks are extended to Dr. Roya Karimi for laboratory procedures and Dr. Ahmad Reza Shamshiri for his help in doing the data analysis. We are also immensely grateful to Dr. Ali Nosrat for his valuable comments and suggestions on an earlier version of the manuscript, although any errors are our own and should not tarnish the reputations of this esteemed person.

\section{References}

1 Hargreaves KM, Diogenes A, Teixeira FB. Treatment options: biological basis of regenerative endodontic procedures. J Endod 2013;39(3, Suppl):S30-S43

2 Jeeruphan T, Jantarat J, Yanpiset K, Suwannapan L, Khewsawai P, Hargreaves KM. Mahidol study 1: comparison of radiographic and survival outcomes of immature teeth treated with either regenerative endodontic or apexification methods: a retrospective study. J Endod 2012;38(10):1330-1336

3 Lovelace TW, Henry MA, Hargreaves KM, Diogenes A. Evaluation of the delivery of mesenchymal stem cells into the root canal space of necrotic immature teeth after clinical regenerative endodontic procedure. J Endod 2011;37(2):133-138

4 Lin LM, Shimizu E, Gibbs JL, Loghin S, Ricucci D. Histologic and histobacteriologic observations of failed revascularization/revitalization therapy: a case report. J Endod 2014;40 (2):291-295

5 Diogenes A, Ruparel NB, Shiloah Y, Hargreaves KM. Regenerative endodontics: a way forward. J Am Dent Assoc 2016;147(5):372-380

6 Chen MY, Chen KL, Chen CA, Tayebaty F, Rosenberg PA, Lin LM. Responses of immature permanent teeth with infected necrotic pulp tissue and apical periodontitis/abscess to revascularization procedures. Int Endod J 2012;45(3):294-305

7 Chueh LH, Huang GT. Immature teeth with periradicular periodontitis or abscess undergoing apexogenesis: a paradigm shift. J Endod 2006;32(12):1205-1213

8 Nosrat A, Seifi A, Asgary S. Regenerative endodontic treatment (revascularization) for necrotic immature permanent molars: a review and report of two cases with a new biomaterial. J Endod 2011;37(4):562-567

9 Trope M. Treatment of the immature tooth with a non-vital pulp and apical periodontitis. Dent Clin North Am 2010;54(2):313-324

10 McTigue DJ, Subramanian K, Kumar A. Case series: management of immature permanent teeth with pulpal necrosis: a case series. Pediatr Dent 2013;35(1):55-60

11 Nosrat A, Li KL, Vir K, Hicks ML, Fouad AF. Is pulp regeneration necessary for root maturation? J Endod 2013;39(10):1291-1295

12 Ruparel NB, Teixeira FB, Ferraz CC, Diogenes A. Direct effect of intracanal medicaments on survival of stem cells of the apical papilla. J Endod 2012;38(10):1372-1375

$13 \mathrm{Kim} \mathrm{JH}$, Kim Y, Shin SJ, Park JW, Jung IY. Tooth discoloration of immature permanent incisor associated with triple antibiotic therapy: a case report. J Endod 2010;36(6):1086-1091

14 Althumairy RI, Teixeira FB, Diogenes A. Effect of dentin conditioning with intracanal medicaments on survival of stem cells of apical papilla. J Endod 2014;40(4):521-525 
15 Labban N, Yassen GH, Windsor LJ, Platt JA. The direct cytotoxic effects of medicaments used in endodontic regeneration on human dental pulp cells. Dent Traumatol 2014;30(6):429-434

16 Diogenes AR, Ruparel NB, Teixeira FB, Hargreaves KM. Translational science in disinfection for regenerative endodontics. J Endod 2014;40(4, Suppl):S52-S57

17 AlSaeed T, Nosrat A, Melo MA, et al. Antibacterial efficacy and discoloration potential of endodontic topical antibiotics. J Endod 2018;44(7):1110-1114

18 Sabrah AH, Yassen GH, Gregory RL. Effectiveness of antibiotic medicaments against biofilm formation of Enterococcus faecalis and Porphyromonas gingivalis. J Endod 2013;39(11):1385-1389

19 Trevino EG, Patwardhan AN, Henry MA, et al. Effect of irrigants on the survival of human stem cells of the apical papilla in a platelet-rich plasma scaffold in human root tips. J Endod 2011;37(8):1109-1115

20 CLSI, Performance Standards for Antimicrobial Susceptibility Testing. 26th ed. CLSI supplement M100S. Wayne, PA: Clinical and Laboratory Standards Institute; 2016

21 Andrews JM. Determination of minimum inhibitory concentrations. J Antimicrob Chemother 2001;48(1, Suppl 1):5-16

$22 \mathrm{Xu} \mathrm{X}, \mathrm{Zhou} \mathrm{XD}, \mathrm{Wu} \mathrm{CD}$. The tea catechin epigallocatechin gallate suppresses cariogenic virulence factors of Streptococcus mutans. Antimicrob Agents Chemother 2011;55(3):1229-1236

23 Fouad AF. The microbial challenge to pulp regeneration. Adv Dent Res 2011;23(3):285-289

24 Sabrah AH, Yassen GH, Liu WC, Goebel WS, Gregory RL, Platt JA. The effect of diluted triple and double antibiotic pastes on dental pulp stem cells and established Enterococcus faecalis biofilm. Clin Oral Investig 2015;19(8):2059-2066

25 Chuensombat S, Khemaleelakul S, Chattipakorn S, Srisuwan T. Cytotoxic effects and antibacterial efficacy of a 3-antibiotic combination: an in vitro study. J Endod 2013;39(6):813-819

26 Kamocki K, Nör JE, Bottino MC. Effects of ciprofloxacin-containing antimicrobial scaffolds on dental pulp stem cell viability-In vitro studies. Arch Oral Biol 2015;60(8):1131-1137

27 Karczewski A, Feitosa SA, Hamer EI, et al. Clindamycin-modified triple antibiotic nanofibers: a stain-free antimicrobial intracanal drug delivery system. J Endod 2018;44(1):155-162

28 Albuquerque MT, Evans JD, Gregory RL, Valera MC, Bottino MC. Antibacterial TAP-mimic electrospun polymer scaffold: effects on P. gingivalis-infected dentin biofilm. Clin Oral Investig 2016;20(2):387-393

29 Galluzzi L, Aaronson SA, Abrams J, et al. Guidelines for the use and interpretation of assays for monitoring cell death in higher eukaryotes. Cell Death Differ 2009;16(8):1093-1107

30 Peters OA. Research that matters - biocompatibility and cytotoxicity screening. Int Endod J 2013;46(3):195-197

31 Alghilan MA, Windsor LJ, Palasuk J, Yassen GH. Attachment and proliferation of dental pulp stem cells on dentine treated with different regenerative endodontic protocols. Int Endod J 2017;50(7):667-675

32 Hosseini Matin M, Zare Jahromi M, Fesharaki M, Ostad Sharif M. Cytotoxicity of triple antibiotic paste and calcium hydroxide against cultured human dental pulp fibroblasts. J Dental School Shahid Beheshti Univ Med Sci 2015;33(3):196-204 